\title{
ACTIVITY COEFFICIENTS. INTERFACIAL TENSIONS AND RETENTION IN REVERSED-PHASE LIQUID CHROMATOGRAPHY ON LICHROSORB RP-18 WITH METHANOL-WATER MIXTURES
}

\author{
W. E. HAMMERS*, G. J. MEURS and C. L. DE LIGNY \\ Laboratory for Analyical Chenistry, State Cniversity, Croesestraat 77.4 .3522 AD Cirecht (The Aether- \\ lasids)
}

(First received November 25th. 1981; revised manuscript receited February 15th, 1982)

\section{SUMMARY}

Literature data on activity coefficients of various solutes in water, of some tetraalkyl compounds in methanol-water mixtures and of water in organic solvents have been correlated with the product of the molecular surface area of the solute and the solute-solvent interfacial tension at ambient temperature. The conditions for which this relationship holds are examined.

The retentions of apolar solutes have been measured on LiChrosorb RP-18 using methanol-water mixtures as eluents at $25^{\circ} \mathrm{C}$. The results are discussed in terms of a monolayer adsorption model (according to Locke-Everett) and in terms of the adsorption model based on the solvophobic interaction theory. The important rôle of solute activity coefficients in the eluent on solute retention is shown quantitatively. The affinity of the adsorbent towards solutes is shown to be a result of apolar interactions in the RP-18 phase and of polar interactions in the interfacial layer of adsorbed methanol. The influence of both contributions is illustrated.

\section{INTRODUCTION}

Deviations from ideal behaviour in solutions of non-electrolytes are frequently important in the design and operation of separation processes. Although the understanding of these deviations has grown considerably during the past decades, it is still a difficult task to predict them quantitatively. Particularly for mixtures containing one or more polar components, one cannot rely on current solution theories because the basic assumptions employed do not apply to polar mixtures. Therefore, in many instances. experimental data on activity coefficients or estimated values from (semi-) empirical correlations have to be used. In this respect the extensive work of Pierotti et al. ${ }^{1}$ on infinite dilution activity coefficients of members of homologous series in water, alcohols and ketones must be mentioned.

The first part of the present work deals with activity coefricients of rather small solute molecules of various sizes, shapes and polarities in water and those of apolar solutes in methanol-water mixtures, and also of water in some organic solvents, at 
ambient temperature. The second part deals with the interpretation of chromatographic retention data of aromatic solutes on LiChrosorb RP-18 with methanol-water mixtures as eluents at $25^{\circ} \mathrm{C}$. It will be shown that current retention theories may give rise to misinterpretations when solute activity coefficients in the eluent are not quantitatively accounted for.

THEORETICAL

\section{Activity coefficients and solubilities}

The excess chemical potential of an infunitely dilute solution of a sparingly soluble liquid solute (1) in a solvent (2) is given by

$$
\Delta \mu_{1.2}^{\mathrm{E}}=R T \ln \gamma_{1.2}^{x}=-R T \ln x_{1.2}
$$

wherein $y_{1.2}^{x}$ is the activity coefficient of the solute at infinite dilution and $x_{1.2}(\leqslant 0.01)$ is the mole fractional solubility of the solute at the absolute temperature, $T$.

In the case of random mixing, $\Delta \mu_{1.2}^{E}$ can be divided in two terms ${ }^{2}$ :

$$
\Delta \mu_{1.2}^{\mathrm{E}}=\Delta \mu_{1.2}^{\mathrm{ath}}+\Delta \mu_{1.2}^{\mathrm{th}}
$$

The athermal contribution arises from the difference in size between the two molecular species in the solution. It is usually estimated from the well known Flory-Huggins equation ${ }^{3.4}$ which, at infinite dilution, is given by

$$
\Delta \mu_{1.2}^{2 t h .}=R T\left[\ln \frac{v_{1}^{0}}{v_{2}^{0}}+\left(1-\frac{r_{2}^{0}}{v_{1}^{0}}\right)\right]
$$

where $v^{0}$ is the molar volume. However, it is questionable whether eqn. 3 is applicable to the partly aqueous solutions examined in this work. First, one can hardly expect that such solutions of apolar solutes obey the condition of random mixing because of preferential solvation of the solutes by the organic solvent. Secondly, Hildebrand and Scott ${ }^{5}$ and Vitoria and Walkley ${ }^{6}$ have shown that the Flory-Huggins equation considerably overestimates the athermal contribution to the excess entropy for mixtures of globular (instead of chain) molecules. Thirdly, according to Flory ${ }^{7}$, eqn. 3 is less suitable when $v_{1}^{0} / r_{2}^{\circ}$ is small (i.e., 2-5). As these features apply to many of our solutions. the $\Delta \mu_{1.2}^{\text {ath }}$ term will be omitted.

To estimate the value of $\Delta \mu_{1.2}^{\text {th }}$ ( or $\Delta \mu_{1.2}^{\mathrm{E}}$ ) the cavity concept is adopted, according to which. the transfer of a solute molecule from the pure liquid to the solvent can be divided into two steps. In the first one the solute molecule is removed from the liquid, the required free energy being equal to $0.5 F_{1,1}^{\mathrm{c}} A_{1} N$, where $F_{1.1}^{\mathrm{c}}$ is the free energy of cohesion (per $\mathrm{cm}^{2}$ ), $N$ is Avogadro's constant and $A_{1}$ the molecular surface area of the solute. In the second step the solute molecule is transferred into a cavity of suitable size (i.e., with a surface area $A_{1}$ ) in the solvent. Beside the free energy of cavity formation in the solvent, equal to $0.5 F_{2,2}^{\mathrm{c}} A_{1} N$, a term $-F_{1.2}^{\mathrm{a}} A_{1} N$ is involved, wherein $-F_{1,2}^{2}$ is equal to the free energy of adhesion (per $\mathrm{cm}^{2}$ ) for the interface between the phases 1 and 2. According to Girifalco and Good ${ }^{8}$

$$
F_{\overline{\mathrm{i}} \mathrm{i}}^{\mathrm{c}}=2 \sigma_{\mathrm{i}}^{\mathrm{o}}
$$


and

$$
F_{1,2}^{\mathrm{a}}=\sigma_{1}^{0}+\sigma_{2}^{0}-\sigma_{12}^{0}
$$

where $\sigma_{i}^{0}$ is the surface tension of $i$ and $\sigma_{12}^{0}$ is the interfacial tension between the phases 1 and 2 . Hence, according to this approach a very simple relation for $\Delta \mu_{1.2}^{\mathrm{E}}$ is obtained:

$$
\Delta \mu_{1.2}^{\mathrm{E}}=\sigma_{12}^{0} A_{1} N
$$

However, it had already been recognized by Uhlig $^{9}$, who correlated the solubilities of gases in organic solvents with $\sigma_{2}^{\circ}$ values, that the use of (macroscopic) surface tension data on a molecular scale implies an approximation. More recently, Choi et al ${ }^{10}$ showed that the curvature of cavities accommodating small molecules like argon can lower the "microscopic" surface tension of apolar solvents to about one-third of the value for a plane surface. Therefore, $\Delta \mu_{1.2}^{\mathrm{E}}$ can be at most proportional to $\sigma_{12}^{0} A_{1} N$.

An even more serious problem arises from the impossibility of giving a sharp definition of a cavity when the ratio of the molecular radii $r_{1} / r_{2} \leqslant 1^{11}$. Further, the underlying assumption on applying eqns. 4 and 5 to the solution process is that macroscopic interfacial layers have similar properties to molecular solvation layers, which is erroneous ${ }^{12}$. In this respect, hydrophobic effects are mentioned which influence the excess entropy, enthalpy and probably also $\Delta \mu_{1,2}^{\mathrm{E}}$ of apolar solutes in aqueous solvents ${ }^{13-15}$. It is not expected that these intricate effects play a similar rôle in plane interfaces. For these reasons, the approach outlined above can only yield an empirical formula for $\Delta \mu_{1,2}^{\mathrm{E}}$, which in its most simple, linear, fom reads:

$$
\Delta \mu_{1,2}^{E} / R T=\ln z_{1.2}^{x}=-\ln x_{1,2}=B+C \sigma_{12}^{0} A_{1} N / R T
$$

In eqn. 7, $B$ and $C$ are adjustable parameters, the magnitude of which may depend on the temperature and the solvent.

A similar relation has been applied by several authors ${ }^{16-18}$ in order to relate the solubilities of members of various solute series (e.g., alkanes, alkylbenzenes and alcohols) in water to their $A_{1}$ values. In this paper it is also applied to solutions in methanol-water mixtures and to solutions of water in organic solvents.

\section{Solute retention in reversed-phase columns}

From a formal point of view an apolar bonded phase should be considered as a solid adsorbent. Owing to its diffuse surface layer, the adsorptive properties may differ from those of "classical" solids. Nevertheless, it seems logical to start with searching for a plausible description of solute retention in terms of adsorption models. This approach is now outlined.

From isotherm data given by Slaats et al. ${ }^{19}$ and BET surface area determined in our laboratory, we estimated that [at $50-90 \%(\mathrm{v} / \mathrm{v})$ methanol] about 0.9 and 1.2 monolayers of eluent (largely methanol) are adsorbed on LiChrosorb RP-8 (272 5 $\left.\mathrm{m}^{2} / \mathrm{g}\right)$ and $\mathrm{RP}-18\left(171 \pm 1 \mathrm{~m}^{2} / \mathrm{g}\right)$, respectively.

The capacity ratio, $k$, of a solute (1), which is distributed between an interfacial layer (2/3) and a mobile eluent (2), can be presented by the equation:

$$
\ln k \equiv \ln \left(\bar{n}_{1} / n_{1}\right)=\ln \left(\gamma_{1,2}^{x} / n_{2}\right)-\ln \left(\gamma_{1,2 / 3}^{x} / \bar{n}_{2}\right)
$$


In eqn. $8, \bar{n}_{1}$ and $n_{1}$ are the numbers of moles of solute in the stagnant interfacial "phase" and the mobile phase. respectively. It is assumed that both phases are homogeneous and contain $\bar{n}_{2}$ moles of adsorbed and $n_{2}$ moles of mobile eluent. respectively. The solute activity coefficients in the mobile phase and in the adsorbed eluent layer are denoted by $i_{1,2}^{x}$ and $\gamma_{1,2 ; 3}^{x}$, respectively, and are both defined with the pure (liquid) solute as standard state.

Following Everett ${ }^{20}$. we adopt his basic concept of monolayer adsorption and chose a monolayer of pure solute as standard state for the solute activity coefficient in the interface. The corresponding activity coefficient, $\bar{\pi}_{1.2,3}^{x}$, is related to $\eta_{1,2,3}^{x}$ by

$$
\ln \eta_{1,2,3}^{x}=\ln \bar{F}_{1,23}^{x}-\bar{A}_{1} N\left(\sigma_{23}^{0}-\sigma_{13}^{0}\right) / R T
$$

where $\bar{A}_{1}$ is the area occupied by a solute molecule on the adsorbent, and $\sigma_{23}^{\circ}$ and $\sigma_{13}^{0}$ are the surface tensions of the adsorbent-eluent and -pure solute interfaces.

Combination of eqns. 8 and 9 gives:

$$
\ln k=\ln \left(\bar{n}_{2} / n_{2}\right)+\ln i_{1.2}^{x}-\ln \bar{n}_{1.2}^{x}{ }_{3}+\bar{A}_{1} N\left(\sigma_{23}^{0}-\sigma_{13}^{0}\right) / R T
$$

This equation was proposed by Locke ${ }^{21}$ on the basis of a displacement adsorption model. He noted that the last two terms of eqn. 10 are not readily predictable for apolar bonded phases. Further. he observed that ln $k$ is strongly correlated with solute solubility in the eluent and concluded that the $\ln \gamma_{1.2}^{x}$ term is of prime importance. Colin and Guiochon ${ }^{22}$, however, proposed to neglect both activity coefficient terms in eqn. 10. With this approximation, $k$ values in the eluents 2 and 2 are related by the equation:

$$
\ln \left(k_{1.2} 3^{i k_{1.2} \cdot 3}\right)=\ln \left(\bar{n}_{2} n_{2} \cdot / n_{2} \bar{n}_{2} \cdot\right)+\bar{A}_{1} N\left(\sigma_{23}^{0}-\sigma_{2 \cdot 3}^{0}\right) ! R T
$$

This simple equation has been used to define an eluent strength scale on the basis of interfacial tension data ${ }^{22.23}$. It can be assumed that $\sigma_{23}^{0}$ values for an alkylsilica and a liquid alkane as component 3 are approximately equal. The latter data can either be measured, or estimated with Fowkes' equation ${ }^{24}$

$$
\sigma_{23}^{\mathrm{o}}=\sigma_{2}^{\mathrm{o}}+\sigma_{3}^{\mathrm{o}}-2\left(\sigma_{2}^{\mathrm{d}} \sigma_{3}^{\mathrm{o}}\right)^{12}
$$

whercin $\sigma_{2}^{\text {d }}$ represents the "dispersive" part of the surface tension of the polar solvent. From eqn. 11. Colin and Guiochon 22 obtained similar $\sigma_{23}^{\circ}-\sigma_{2 \cdot 3}^{\circ}$ values for ODS-2 (a bound octadecyl silyl phase) and graphite in water (2) and methanol (2'). Moreover, these values were in accord with calculated estimates. The authors concluded that this res!lt points to an adsorption mechanism on ODS-2. However, from Fig. 7 and 8 of ref. 22 it follows that in methanol-water mixtures the eluent strength depends on the solute type. This inconsistency needs closer examination.

Another adsorption model has been proposed by Horváth et $a .^{25}$. It is based on Sinanoğlu's solvophobic interaction theory ${ }^{26}$, which gives a detailed account of non-electrolyte-solvent interactions in terms of macroscopic properties of the mixture components. A disadvantage of Horvath's equation ${ }^{25}$ for $\ln k$ is that eluent and adsorbent effects are mingled in the various terms, which hampers a rigorous verif- 
cation of his model. As far as eluent effects on retention are concerned, this difficulty can be overcome. In the Appendix, it is shown that the relation between the solute activity coefficients in the eluents 2 and $2^{\prime}$ is given by:

$\ln \left(\ddot{\gamma}_{1.2}^{x} / \gamma_{1,2}^{x}\right)=\left(\Delta \mathrm{F}_{1.2}^{\mathrm{int}}-\Delta \mathrm{F}_{1.2}^{\mathrm{int}}\right) / R T-\ln \frac{l_{2}^{0}}{l_{2}^{0}}+\left[\kappa_{2}^{-}(1) \sigma_{2}^{0}-\kappa_{2}^{\mathrm{e}} \cdot(1) \sigma_{2}^{0} \cdot\right] \cdot A_{1} N_{i} R T$

The first term of the right-hand side of eqn. 13 accounts for the reduced molar free energies of 1-2 and 1-2' interaction contributions. The second one represents the change of the reduced translational free energy of the solute on its transfer from eluent 2' to eluent 2. The parameter $\kappa^{-}(1)$ in the third term corrects for the effect of curvature of the cavity surface on the macroscopic surface tension of the solvent and depends on the solvent and the solute. Eqn. 13 may be compared with the empirica! eqn. 7 and eqn. 12.

As is outlined in the Appendix, ln $k$ values in the eluents 2 and 2 are related by:

$$
\begin{aligned}
\ln \left(k_{1.2 ; 3} / k_{1.2 ; 3}\right)= & \ln \left(\bar{n}_{2} n_{2} \cdot / n_{2} \bar{n}_{2}\right)+\ln \left(y_{1,2}^{x} / ;_{1,2}^{x}\right)- \\
& {\left[k_{2}^{-}(3) \sigma_{2}^{0}-k_{2}^{e} \cdot(3) \sigma_{2}^{0}\right]\left(A_{13}-A_{3}\right) N / R T }
\end{aligned}
$$

In eqn. 14, the index 13 denotes the association complex of the solute and a bonded phase alkyl chain. The occurrence of "free" alkyl chains in RP-18 layers in contact with polar eluents is not certain. It cannot be ruled out that the alkyl chains are associated in a more or less "rough" surface layer. Only for a perfectly plane surface does it hold that $\kappa_{2}^{e}(3)=\kappa_{2}^{e} \cdot(3) \approx 1$ (cavity curvature is nil). Furtiner. the factor $A_{13}-$ $A_{3}$ in eqn. 14 is not predictable, unless the RP-18 surface layer is smooth. Finally, in partly aqueous eluents the concentration of the organic modifier around a solute molecule will deviate from that in a macroscopic surface layer. In consequence, $x^{*}$ values cannot be predicted for mixed solvents ${ }^{26}$ and eqns. 13 and 14 can only be applied rigorously when neat eluents are used.

The concept of retention by liquid-liquid partition implies that a homogeneous solution of the solute (1) in the RP-18 phase (3) is assumed. In this case $k$ values holding in eluent 2 are described by

$$
\ln k=\ln \left(\bar{n}_{1} / n_{1}\right)=\ln \left(7_{1,2}^{x} / n_{2}\right)-\ln \left(\gamma_{1,3}^{x} / n_{3}\right)
$$

wherein $7_{1.3}^{\infty}$ is the solute activity coefficient in the RP-18 phase and $n_{3}$ is the number of moles of octadecyl groups in the column. The distribution of a solute between a solvent (2) and a suitable $n$-alkane phase $\left(3^{\prime}\right)$ is given by the partition coefficient. $P$

$$
\ln P=\ln \left(c_{1,3} / c_{1.2}\right)=\ln \left(\ddot{\gamma}_{1,2}^{x} v_{2}^{0}\right)-\ln \left(\ddot{r}_{1.3}^{x} \cdot v_{3}^{0}\right)
$$

where $c_{1,3}$ and $c_{1.2}$ are solute concentrations (mole/1) in both phases. Combination of eqns. 15 and 16 yields

$$
\ln k=\ln \left(n_{3} v_{3}^{0} \cdot / V_{\mathrm{m}}\right)-\ln \left(\gamma_{1,3}^{x} / \gamma_{1,3}^{x}\right)+\ln P
$$


Where $V_{\mathrm{m}}=n_{2} r_{2}^{0}$. Unfortunately, $\ln \gamma_{1,3}^{x}$ cannot be measured. The best thing to do is to suppose $\gamma_{1.3}^{x}$ to be equal to $\gamma_{1.3}^{\infty}$. Hence, a partition mechanism is only plausible when $k$ values obey the relation $k / P=n_{3} v_{3}^{0} / V_{\mathrm{m}^{2}}$. With this criterion in mind it is possible to estimate the relative importance of partition contributions to $k$ values from experimental $\ln k$ versus $\ln P$ plots with an intercept $\ln \delta$ and a slope equal to 1 . Under these conditions, it holds that

$$
k_{\text {part. }} / k=n_{3} r_{3}^{0} / \delta V_{m}
$$

wherein $k_{\text {part. }}$ denotes the contribution of solute partition to $k$. When $\delta$ appears to be much larger than the estimated phase ratio. the retention mechanism should be characterized as adsorption. This applies to the $\ln k$ values in this work, as will be shown below.

Finally. it is noted that partial immersion of the solute in the RP-18 layer cannot be ruled out. This will hamper a straightforward interpretation of solute retention in terms of the (displacement) adsorption models mentioned above.

EXPERIMENTAL

\section{Chemicals and characteri=ation of the column packing material}

Ali solutes had the highest available purity. Water was distilled twice before use. Absolute methanol (analyzed reagent grade) was obtained from J. T. Baker (Deventer, The Netherlands). Tetradecane (Fluka, Buchs, Switzerland) was olefinfree. Elemental analysis showed that LiChrosorb RP-18 (E. Merck, Darmstadt. G.F.R.) contains $0.286 \mathrm{~g}$ carbon per gram of the parent silica, LiChrosorb Si 100 $\left(S_{\mathrm{BET}}=282 \mathrm{~m}^{2} / \mathrm{g}\right.$ according to Hemetsberger et $\left.a l_{.}^{27}\right)$. The ODS surface concentration is $4.4 \mu \mathrm{mole} / \mathrm{m}^{2}$ if it is assumed that dichloromethyloctadecylsilane has reacted with the silica. In view of the rather large ODS content, it is not ruled out that traces of water have caused some polymerization of the aikyl layer during the silylation reaction.

\section{Determination of interfacial tensions}

Interfacial tensions of tetradecane/methanol-water mixtures were measured at $20 \pm 0.05^{\circ} \mathrm{C}$ by means of the drop-weight method ${ }^{28}$. The capillary tip of the stalagmometer (glass. $9.5 \mathrm{~mm}$ O.D.) was roughened in order to improve the wetting with highly aqueous phases. The densities of the pure and the presaturated phases were determined by picnometry (accuracy better than $0.2 \%$ ). The methanol-water mixtures were supplied with a calibrated microburette (Metrohm AG Herisau) via a heat exchanger tube to the capillary. The volume of the falling drop was determined after an equilibration time of $5 \mathrm{~min}$ (at $95 \%$ of its final volume). A correction for non-ideal drop shape was applied ${ }^{28}$. The $\sigma_{12}^{0}$ values were reproducible within $0.2 \mathrm{dyne} / \mathrm{cm}$ and appeared to be (within error) the same for pure and presaturated phases. Smoothed values are given in Table $I I$.

\section{Apparatus and procedure for liquid chromatography}

The home-made apparatus was equipped with an Orlita diaphragm pump, two pulse dampeners in series, a four-port Valco sample valve with a 3- $\mu$ loop and an 
Altex M153 UV-detector. The column (precision-bore stainless steel, $25 \mathrm{~cm} \times 2.1$ $\mathrm{mm}$ I.D.) was surrounded by a water-jacket and thermostatted by a circulation pump at $25 \pm 0.05^{\circ} \mathrm{C}$. The eluent flow-rate was monitored continuously with a siphon counter (Waters Assoc., Milford. MA, U.S.A.) which was calibrated at various flowrates and eluent compositions. The column was packed by the viscosity packing method. The slurry [10\% (w/w) RP-18 in amyl alcohol] was degassed and homogenized by sonication, and forced into the column with methanol at $350 \mathrm{~atm}$. The weight of RP-18 in the column was $0.485 \mathrm{~g}$.

The solute sample size was $20 \mu \mathrm{g}$ or less. The reproducibility of triplicate measurements of the retention volume was $10 \mu \mathrm{l}$ or $2 \%$ for strongly retained solutes. Methanol-water mixtures were used as eluents.

The void volume of the column, $V_{0}$, was determined by picnometry using carbon tetrachloride and $n$-hexane. A value of $658 \mu \mathrm{l}$ was obtained. Owing to adsorbed methanol and water [according to Slaats et al. ${ }^{19}, 63 \mu \mathrm{l} / \mathrm{g}$ LiChrosorb RP-18 at eluent compositions ranging from 50 to $90 \%(v / v)$ methanol], the mobile phase volume in the column, $V_{m}$, is equal to $658-0.485 \cdot 63=627 \mu l$. This estimate was used to obtain capacity ratios $k=\left(V_{\mathrm{r}}-V_{\mathrm{m}}\right) / V_{\mathrm{m}}\left(V_{\mathrm{r}}\right.$ is the solute retention volume after correction for hold-up outside the column), also at $30 \%(\mathrm{v} / \mathrm{v})$ methanol.

If the capacity ratio is calculated from $k=\left(V_{\mathrm{r}}-V_{0}\right) / V_{0}$, it has a well defined physical meaning in terms of the surface excess of the adsorbed solute. Moreover. $V_{0}$ can be measured and applied straightforwardly, when the wetting conditions are good. On the other hand, physical models which consider the distribution of the solute between the eluent and a layer of stationary liquid should be examined with $k$ values calculated from $k=\left(V_{\mathrm{r}}-V_{\mathrm{m}}\right) / V_{\mathrm{m}}$, where $V_{\mathrm{m}}$ is equal to $V_{\mathrm{o}}-V_{\mathrm{s}}$ and $V_{\mathrm{s}}$ is the volume of adsorbed eluent. This volume may be estimated from surface excess data of the eluent components, on the basis of some simplifying assumptions ${ }^{19}$.

\section{RESULTS AND DISCUSSION}

\section{Activity coefficients and solubilities}

Solubilities in water. Literature data on $\ln x_{1,2}$ (at $25^{\circ} \mathrm{C}$ ), $\sigma_{1}^{0}$ and $\sigma_{12}^{0}$ data (both at $20^{\circ} \mathrm{C}$ ) and $A_{1}$ values of some alkanes. substituted benzenes. diethyl ether. some alcohols and ketones are given in Table I. Unfortunately, surface tension data are commonly reported at $20^{\circ} \mathrm{C}$. However, since the influence of temperature on $\sigma^{\circ}$ values is rather small $\left(\mathrm{d} \sigma^{\circ} / \mathrm{d} T \approx-0.15\right.$ dyne $/ \mathrm{cm}{ }^{\circ} \mathrm{K}$ for water at $25^{\circ} \mathrm{C}$ ), this disparity of temperatures causes an error of only $-0.7 \mathrm{dyne} / \mathrm{cm}$ which is close to the experimental error of $\sigma_{12}^{0}$ (see Table I) and will not alter the final conclusions.

As the collected $x_{1,2}$ values are small, $\ln \gamma_{1,2}^{\infty}$ values can be calculated from eqn. 1. They are plotted versus $\sigma_{12}^{0} A_{1} N / R T\left(T=298.2^{\circ} \mathrm{K}\right)$ in Fig. 1. Obviously, the solutes can be divided in two classes. The data points of solutes with $10 \leqslant \sigma_{12}^{0}($ dyne/cm) $\leqslant$ 50 can be fitted with the equation

$$
\ln \gamma_{1.2}^{x}=(2.34 \pm 0.14)+(0.619 \pm 0.009) \sigma_{12}^{0} A_{1} N / R T
$$

with a standard error of fit, $s_{\mathrm{f}}=0.18^{\star}$. The $\ln \gamma_{1.2}^{x}$ values of solutes with $\sigma_{12}^{0} \leqq 10$

* Eqn. 19 is not applicable to $n$-alkanes when the number of carbon atoms $n_{c}<5$ or $>11$. 
TABLE I

\section{SOZUBILITIES OF ORGANIC COMPOUNDS IN WATER}

Literature data on $A_{1}, \sigma_{1}^{0}, \sigma_{12}^{0}, \ln x_{1,2}$ and calculated values of $\Phi$ (see eqn. 20).

\begin{tabular}{|c|c|c|c|c|c|}
\hline Solute & $\begin{array}{l}A_{1} \\
\left(A^{2}\right)\end{array}$ & $\begin{array}{l}\sigma_{1}^{0}\left(20^{\circ} \mathrm{C}\right) \\
\left.\left(d_{y}\right) / \mathrm{cm}\right)\end{array}$ & $\begin{array}{l}\sigma_{12}^{0}\left(20^{\circ} \mathrm{C}\right) \\
\left(d_{y n e} / \mathrm{cm}\right)\end{array}$ & $\begin{array}{l}-\ln x_{1.2} \\
\left(25^{\circ} c\right)^{2}\end{array}$ & $\Phi\left(20^{\circ} \mathrm{C}\right)$ \\
\hline Alkanes & ref. 29 & ref. 30 & ref. 30 & ref. 31 & \\
\hline$n$-Pentane & 124.0 & 15.98 & $49.6 \pm 0.6$ & 11.55 & 0.57 \\
\hline 2-Methylbutane & 121.1 & 14.97 & 49.6 & 11.32 & 0.58 \\
\hline$n$-Hexane & 142.1 & 18.42 & $51.0 \div 0.2$ & 13.13 & 0.55 \\
\hline 2,2-Dimethylbutane & 135.1 & 16.18 & $\approx 49.7$ & 12.47 & 0.57 \\
\hline 3-Methylpentane & 137.5 & 18.11 & $\approx 49.9$ & 1284 & 0.56 \\
\hline Cyclohexane & 120.8 & $25.5^{8}$ & $50.2^{8}$ & 11.34 & 0.56 \\
\hline$r$-Heptane & 160.3 & 20.26 & $51.3 \pm 0.8$ & 14.46 & 0.54 \\
\hline 2,4-Dimethylpentane & 154.2 & 18.12 & $\approx 50.0$ & 14.13 & 0.56 \\
\hline$\pi$-Octane & 178.4 & 21.80 & 51.4 & 16.08 & 0.54 \\
\hline 22,4-Trimethylpentane & 163.1 & 18.85 & 50.1 & 14.77 & 0.56 \\
\hline Substituted benzenes & ref. 18 & refs. $s, 30$ & refs. 8,30 & refs. 18,32 & \\
\hline Benzere & 109.5 & 2288 & $34.6 \pm 0.5$ & 7.79 & 0.75 \\
\hline I.sluene & $127.3 *$ & 28.53 & $35.9 \div 0.2$ & $9 . i 7$ & 0.72 \\
\hline Ethylbenzene & $145^{\star \star}$ & 29.04 & $38.1 \pm 0.7$ & 10.49 & 0.69 \\
\hline$c$-Xylene & $143^{\star}$ & 30.00 & 36.1 & 10.44 & 0.71 \\
\hline$m_{i}$-Xylene & $145.1 *$ & 28.60 & 37.9 & 10.60 & 0.70 \\
\hline p-Xylene & $145.1 *$ & 28.33 & 37.8 & 10.53 & 0.70 \\
\hline 1.3,5-Trimethylbenzene & $162.8 *$ & 28.8 & 38.7 & $1 \mathrm{i} .85$ & 0.68 \\
\hline r-Butylbenzene & $182 \star \star$ & 29.33 & 39.6 & 13.36 & 0.68 \\
\hline Chlorobenzene & 127.1 & 33.6 & 37.4 & 9.43 & 0.70 \\
\hline Bromobenzene & 133.1 & 36.5 & 38.1 & 10.10 & 0.69 \\
\hline Iodobenzene & 141.9 & 39.7 & 41.8 & 10.81 & 0.66 \\
\hline Nitrobenzene & $\approx 145^{\star}$ & 43.9 & 25.7 & $8.31^{33}$ & 0.81 \\
\hline Aniline $\star \star$ & $124 \star$ & 42.9 & 5.8 & $4.96^{33}$ & 0.98 \\
\hline Diethyl ether & $113^{3}$ & 17.0 & 10.7 & $4.17^{34}$ & 1.12 \\
\hline Alcohols ${ }^{\star \star \star}$ & ref. 29 & ref. 8 & ref. 8 & ref. 35 & \\
\hline$n$-Pentanol & 134.0 & 25.7 & 4.4 & 5.40 & 1.09 \\
\hline "Hexanol & 1521 & 25.8 & 6.8 & 6.81 & 1.06 \\
\hline Cyclohexanol & 130.3 & 32.7 & 3.9 & 5.10 & 1.04 \\
\hline n-Heptanol & 170.3 & 24.5 & 7.7 & 8.18 & 1.06 \\
\hline n-Octanol & 188.4 & 27.5 & 8.5 & 9.42 & 1.03 \\
\hline Ketones $x \times$ & & ref. 8 & ref. $s$ & ref. 34 & \\
\hline Methyi propyl ketone & $127^{\frac{\pi}{2}}$ & 24.7 & 6.3 & 4.33 & 1.07 \\
\hline Methyl butyl ketone & $146^{*}$ & 25.0 & 9.6 & 5.30 & 1.03 \\
\hline Methyl amyl ketone & $164^{:}$ & 26.2 & 12.4 & 5.78 & 0.99 \\
\hline
\end{tabular}

* Vaiues estimated from Van der Waals radii ${ }^{36}$. bond lengths and bond angles, as outlined by Vaivani et al. $^{29}$, using their $A$ values for nomomorphous chlorobenzenes ${ }^{18}$ as reference compounds.

* Estimates from the plot of $\ln x_{12}$ values of methylated benzenes versus $A_{1}$ values.

$\star \star \star *$ Excluded from the regression.

5 Valus obtained from the plot of $A_{1}$ values of $n$-alkanes (given by Valvani et al. ${ }^{39}$ ) versus those according to Bondi ${ }^{36}$, and using his $A$ increments for the $-O$ and $\chi C=O$ groups. 
dyne/cm (aniline, alcohols and ketones) cannot be predicted with eqn. 19. Possibly, oriented adsorption of these molecules at the water interface occurs which causes an anomalously low value of $\sigma_{12}^{0}$. Attention is focused on the first mentioned solute class. For these solutes, the precision of eqn. 19 is diminished by correcting $\ln \gamma_{1,2}^{x}$ for the athermal contribution to the excess entropy (see Fig. 1).

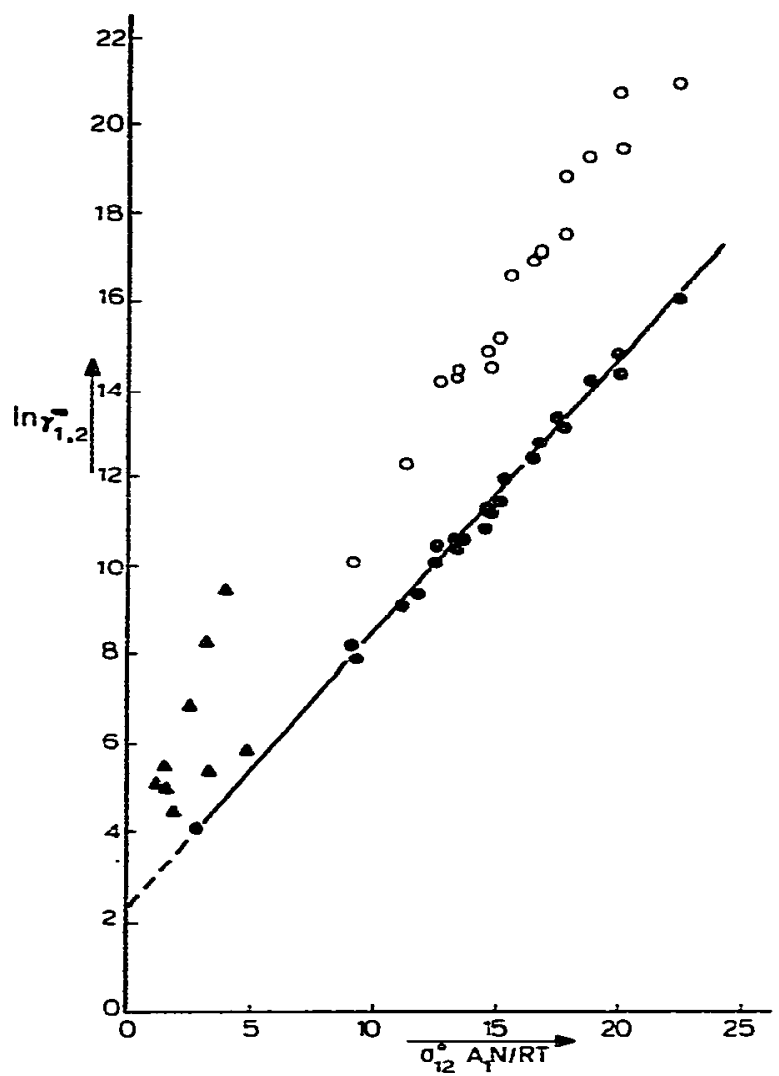

Fig. 1. Literature data on $\ln \eta_{1.2}^{x}$ in water at $25^{\circ} \mathrm{C}$ of solutes with interfacial tensions $\sigma_{12}^{0} \geq 10$ dyne/cm (0), and of solutes with $\sigma_{12}^{\circ} \lesssim 10 \mathrm{dyne} / \mathrm{cm}$ (denoted by $\star \star \star$ in Table I, $A$ ), versus $\sigma_{12}^{\circ} A_{1} N / R T$. Aiso presented are $\ln \dddot{y}_{1.2}^{x}-4 \mu_{1.2}^{2 t h} / R T$ data (eqns. 1-3) for alkanes and alkylbenzenes $(O)$.

As eqn. 19 appears to hold remarkably well for solute molecules of different sizes, shapes and polarities (dipole moments), it is interesting to examine the range of deviations from the Berthelot geometric mean rule that is covered by the examined solutions. These deviations hamper a straightforward application of the regular solution theory ${ }^{5}$ in many cases. According to Girifalco and Good ${ }^{8}$ they can be quantized by:

$$
\Phi=F_{1.2}^{\mathrm{a}} /\left(F_{1.1}^{\mathrm{c}} F_{2.2}^{\mathrm{c}}\right)^{1 / 2}=0.5\left(\sigma_{1}^{0}+\sigma_{2}^{0}-\sigma_{12}^{0}\right) /\left(\sigma_{1}^{0} \sigma_{2}^{0}\right)^{1 / 2}
$$

Values of $\Phi$ are given in the last column of Table $I$. Very large deviations are found for alkanes in water $(\Phi=0.56)$ whereas for diethylether in water $\Phi=1.12$ indicates 
only small devidtions. Therefore eqn. 19 holds well over a large range of deviations from the geometric mean rule.

Solubilities in methanol-nater mixtures. Methanol-water mixtures are frequently used as eluent in reversed-phase liquid chromatography. Hence, some insight into the factors which determine $i_{1.2}^{x}$ values in these mixtures can be useful in chromatographic practice and in systematic studies on solute retention. The following analysis merely deals with hydrocarbons.

Literature ${ }^{3 \overline{7}}$ data on $\ln \gamma_{1.2}^{x}$ of tetramethyl-silicon (TMSi), -germanium (TMGe) and -tin (TMSn), tetraethyl-carbon (TEC), -silicon (TESi) and -tin (TESn) and tetrapropylgermanium (TPGe) are given in Table II. From Table I it follows that the $\sigma_{12}^{0}$ values for normal and branched alkanes are about equal. Therefore it was assumed that the $\sigma_{12}^{0}$ values of the tetraalkyl compounds in contact with water are equal to $51.4 \mathrm{dyne} / \mathrm{cm}$ (i.e., the value for n-octane). The $\sigma_{12}^{0}$ values of the tetraalkyl compounds in contact with methanol-water mixtures and methanol were assumed to be equal to $\sigma_{12}^{0}$ of tetradecańe. The latter quantity was measured by the authors and is given in Table II (third line from bottom). The $A_{1}$ values of the tetraalkyl compounds were estimated from their $\ln \because_{1.2}^{x}$ data in water by means of eqn. 19 and are given in Table II (last column). Apart from the data on TEC and two data on TPGe, all $\ln ; r_{1.2}^{x}$ data can accurately be described as linear functions of $\sigma_{12}^{0} A_{1}$ with eqn. 7 . The estimates of the $B$ parameter appear to be independent of the solvent composition and equal to that given in eqn. 19, whereas the estimates of the $C$ parameter (given in Table II) appear to be equal to 1 for $x(\mathrm{MeOH}) \geqslant 0.3$. In order to verify whether $C$ depends on the molecular shape of the solute, incremental $\ln \gamma^{x}$ data for a $-\mathrm{CH}_{2}-$ group, obtained from solubility data given by Hiller et al. ${ }^{38}$ were considered. Ln $\left({ }^{\times}\right)_{\mathrm{CH}_{2}}$ data for $n$-alkyl bromides at $x(\mathrm{MeOH})=0.29$, for $n$-alkylbenzenes at

TABLE II

SOLUBILITIES OF TETRAALKYL COMPOUNDS IN METHANOL (MEOH)-WATER MIXTURES

Literature data on In $\ddot{\prime}_{1.2}^{x}$, calculated values of $A_{1}$. experimental $\sigma_{12}^{0}$ data and values of the $C$ parameter with their standard errors.

\begin{tabular}{|c|c|c|c|c|c|c|c|c|c|}
\hline $\begin{array}{l}x(\text { MeOr }) \\
{ }_{0}(w, w): M E O H\end{array}$ & $\begin{array}{l}0.000 \\
0.00\end{array}$ & $\begin{array}{c}0.059 \\
10.00\end{array}$ & $\begin{array}{l}0.200 \\
30.83\end{array}$ & $\begin{array}{r}0.299 \\
43.12 \\
\end{array}$ & $\begin{array}{c}0.399 \\
54.19 \\
\end{array}$ & $\begin{array}{r}0.491 \\
63.16 \\
\end{array}$ & $\begin{array}{l}0.800 \\
87.68\end{array}$ & $\begin{array}{l}1.000 \\
100.0\end{array}$ & \\
\hline Sointe & $\ln : 7_{1.2}{ }^{37}$ & & & & & & & & $A_{1}\left(A^{2}\right)$ \\
\hline TMSi & 12.43 & 11.73 & & 8.91 & & & 4.52 & 3.68 & 130.5 \\
\hline TMGe & 12.62 & 11.88 & & 8.87 & & & 4.45 & 3.73 & 132.9 \\
\hline TMSn & 12.67 & 11.97 & 10.27 & 9.10 & 7.89 & & 4.69 & 3.83 & 133.6 \\
\hline TEC & 15.59 & 14.74 & 12.68 & 11.26 & 9.75 & & 5.54 & 4.35 & $\approx 175.5$ \\
\hline TESi & 17.04 & 16.03 & 13.58 & 11.89 & 10.15 & 9.03 & 5.77 & 4.54 & 190.0 \\
\hline TESn & 17.70 & 16.63 & 14.06 & 12.27 & 10.44 & 9.27 & 5.63 & 4.29 & 198.5 \\
\hline TPGe & 21.24 & 19.98 & & 14.83 & 12.67 & & $6.97^{\star}$ & $5.87^{\star}$ & 241.3 \\
\hline$\sigma_{12}^{0}($ dyne, $\mathrm{cm})$ & $51.4 \star \star$ & 38.4 & 26.2 & 21.0 & 17.2 & 14.0 & 7.2 & 4.4 & \\
\hline$c$ & 0.619 & 0.77 & 0.93 & 0.99 & 0.99 & 1.04 & 0.99 & 1.02 & \\
\hline$s=$ & 0.008 & 0.01 & 0.01 & 0.02 & 0.05 & & 0.13 & 0.20 & \\
\hline
\end{tabular}

$\star$ Oudier, excluded from regression analyses.

$\star \star$ Datum for $n$-octane-water ${ }^{30}$. 
$x(\mathrm{MeOH})=0.36$ and for $n$-alkyl disulphides at $x(\mathrm{MeOH})=0.51$ are: $0.92 \pm 0.05$, $0.82 \pm 0.04$ and 0.59 , respectively. The corresponding $C \sigma_{12}^{0}$ vaiues lie on the same curve as those for the tetraalkyl compounds in a plot vs. the composition of the solvent (Fig. 2). As the appropriate value of $\sigma_{12}^{0}$ of a $-\mathrm{CH}_{2}-$ group may be assumed to be equal to that of tetraalkyl compounds, this result means that $C$ is also equal to 1 for the $-\mathrm{CH}_{2}-$ group.

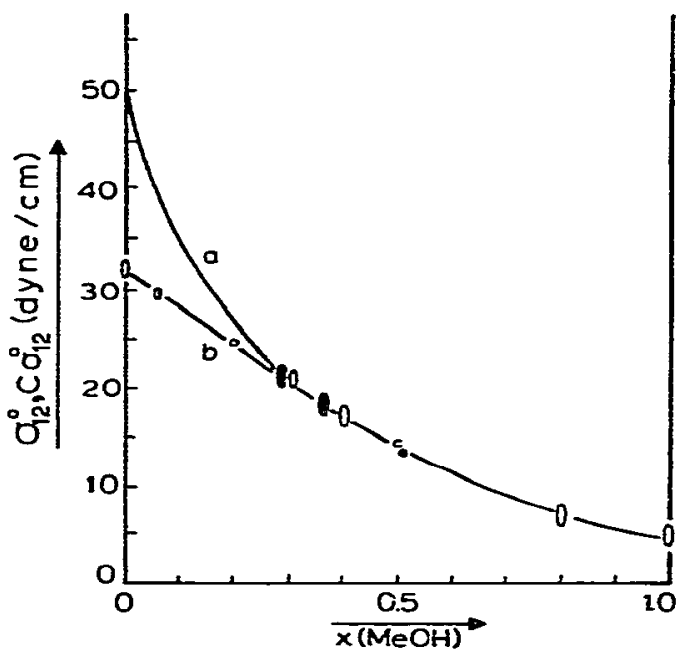

Fig. 2. Macroscopic $\sigma_{12}^{0}$ values for the planar interface tetradecane/methanol-water (a), and microscopic $C \sigma_{1=}^{0}$ values for the curved molecular interface of tetraalkyl compounds $(O)$ and of a $-\mathrm{CH}_{2}-$ group in $n$ alkyl-bromides. -benzenes and -disulphides $(\bullet)$ in methanol-water mixtures (b), as a function of the mole fraction of methanol at $20^{\circ} \mathrm{C}$. Values of $\mathrm{C \sigma}_{12}^{0}$ have been calculated from solubilities by eqn. 19.

Solubility of water in organic solvents. Data on in $x_{1,2}(1 \sim$ water, $2 \sim$ organic solvent) given by Donahue and Bartell ${ }^{33}$ are used. In order to avoid artifacts due to concentration effects on $\gamma_{1,2}$, we considered only those solutions where $x_{1,2}<0.01$. The selected data on $\ln x_{1,2}, \sigma_{2}^{0}$ and $\sigma_{12}^{0}$ and the calculated $\Phi$ values are given in Table III.

A description of the In $\gamma_{1.2}^{x}$ data in terms of eqn. 7 requires a value for the surface area of the cavity which can accommodate a water molecule. We assumed that it is equal to the surface area of a water molecule ( $36 \AA^{2}$, as calculated according to $\left.B o n d i^{36}\right)$. The $\ln \gamma_{1,2}^{x}$ data can be described fairly well with the equation

$$
\ln \gamma_{1,2}^{x}=(2.17 \pm 0.39)+(1.17 \pm 0.10) A A_{1} N \sigma_{12}^{0} / R T
$$

with a standard error of fit, $s_{\mathrm{f}}=0.25$. The value of the $B$ parameter is about equal to that given in eqn. 19 , whereas the value of $C$ is rather close to 1 (i.e., the value estimated in the preceding section).

The rather good description of the $\ln \gamma_{1,2}^{\infty}$ data with eqns. 19 and 21 illustrates the well known fact that free energies can generally be well described with rather crude models. On the other hand, it is true that free energy data can only vield a limited insight into the intricate phenomena that are encountered in physical reality. Therefore we do not want to speculate about the physical meaning of the empirical 
TABLE III

SOLUBILITIES OF WATER IN ORGANIC SOLVENTS

Literature data on $\sigma_{2}^{0}, \sigma_{12}^{0}$ and in $x_{1,2}$, and calculated values of $\Phi$ (see eqn. 20 ).

\begin{tabular}{|c|c|c|c|c|}
\hline Solvent & $\begin{array}{l}\sigma_{2}^{0}\left(20^{\circ} \mathrm{C}\right) \\
\left(d_{1}\left(\mathrm{ne} e_{l}^{\prime} \mathrm{cm}\right)\right.\end{array}$ & $\begin{array}{l}\sigma_{12}^{\circ}\left(20^{\circ} \mathrm{C}\right) \\
\left(d_{1} \text { ine }{ }^{\prime} \mathrm{cm}\right)\end{array}$ & $-\ln x_{1.2}{ }^{33}$ & $\Phi\left(20^{\circ} \mathrm{C}\right)$ \\
\hline Alkanes & ref. 30 & ref. 30 & & \\
\hline$n$-Pentane & 15.98 & 49.6 & 7.64 & 0.57 \\
\hline$n$-Hexane & 18.42 & 51.0 & 7.42 & 0.55 \\
\hline Cyclohexane & $25.5^{-5}$ & $50.2^{8}$ & 7.51 & 0.56 \\
\hline$n$-Heptane & 20.26 & 51.3 & 7.08 & 0.54 \\
\hline n-Octane & 21.80 & 51.4 & 7.01 & 0.54 \\
\hline Subsrituted ben:enes & ref. 30 & ref. 30 & & \\
\hline Benzene & 22.88 & 34.6 & 5.78 & 0.75 \\
\hline Toluene & 28.53 & 35.9 & 5.99 & 0.72 \\
\hline Eth!lbenzene & 29.04 & 38.1 & 6.07 & 0.69 \\
\hline Bromobenzene & $36.5^{3}$ & $38.1^{3}$ & 5.84 & 0.69 \\
\hline Halogerated alkanes & ref. 8 & ref. 8 & & \\
\hline Chloroform & 27.15 & 31.6 & 5.30 & 0.77 \\
\hline Carbon tetrachloride & 26.95 & 45.0 & 7.09 & 0.62 \\
\hline Ethyl bromide & 24.2 & 31.2 & 5.34 & 0.78 \\
\hline Carbon disulphide & 32.3 & 48.4 & 7.26 & 0.58 \\
\hline
\end{tabular}

parameters $B$ and $C$. An analogous reservation applies to the following discussion of the retention on reversed-phase adsorbents.

We conclude this section by stating that eqn. 7 gives a good description of activity coefficients (i.e., solubilities) in solvents as different as water, partly aqueous solvents and apolar organic solvents. This equation contains only two parameters, one of which $(B)$ appears to be independent of the solvent.

Retention of apolar solutes on LiChrosorb RP-18 in methanol-uater systems

Ln $k$ values in water were obtained by linear extrapolation of experimental $\ln k$ data $(k \leqslant 65)$ at $30,50,70$ and $90 \%(v / v)$ methanol. These values as well as the slopes of plots of In $k$ versus the volume fraction of methanol $(b)$ are given in Table IV for some alkylbenzenes, chlorobenzenes and arenes. It is noted that the extrapolated data in water (2) and methanol (2') may deviate slightly from experimental data. At high water contents $[\geq 80 \%(\mathrm{v} / \mathrm{v})]$ the experimental results may be affected by incomplete wetting of the alkyl layer. For ${ }^{2} \mathrm{H}_{2} \mathrm{O}, V_{\mathrm{r}}=555 \mu \mathrm{l}$ was obtained in water. A similar relatively smail value has been reported by McCormick and $\mathrm{Karger}^{41}$. Nevertheless, Karger et $a l^{\text {s2 }}$ obtained in $k$ values for some $n$-alcohols with methanol-water mixtures and water as eluents, which are linearly related to the volume fraction of methanol. Our (extrapolated) In $(k)_{\mathrm{CH}_{2}}$ values in water (from ln $k$ values of butyl- and propylbenzene) are within error equal to those presented by Karger et al. In view of possible effects on in $k$ at high water contents, only relative ln $k$ values of related solutes in water will be considered below.

Colin's model (eqn. 11). In order to examine the applicability of eqn. 11 to LiChrosorb RP-18, $b$ values were plotted versus $A_{1} N / R T$. The solute surface fraction 
TABLE IV

VALUES FOR $A_{1}$ - EXTRAPOLATED in $k$ VALUES ON LICHROSORB RP-18 HOLDING FOR WATER AS ELUENT, In $\eta_{1.2}^{x}$ AND $\ln \left(k / y_{1.2}^{x}\right)$ VALUES IN WATER AND THE SLOPES OF PLOTS OF In $k$ versUS VOLUME FRACTION METHANOL, $b$

\begin{tabular}{|c|c|c|c|c|c|}
\hline Solute & $A_{1}\left(A^{2}\right)$ & $\ln k \pm s$ & $\ln \dddot{\gamma}_{1.2}^{x}$ & $-\ln \left(k / y_{1.2}^{x}\right)$ & $-b \pm s$ \\
\hline Alky/benzenes & & & ref: 32 & & \\
\hline Benzene & 109.5 & $4.86 \pm 0.12$ & $7.79^{18}$ & 2.93 & $6.24 \pm 0.16$ \\
\hline Toluene & 127.3 & $6.31 \div 0.12$ & 9.17 & 2.86 & $7.55 \pm 0.18$ \\
\hline o-Xylene & 143 & $7.35 \doteqdot 0.07$ & 10.44 & 3.09 & S.38 $\doteq 0.09$ \\
\hline$m$-Xylene & 145.1 & $7.60 \pm 0.09$ & 10.60 & 3.00 & $8.61 \pm 0.14$ \\
\hline$p$-Xylene & 145.1 & $7.58 \pm 0.05$ & 10.53 & 2.95 & $8.50 \div 0.05$ \\
\hline Ethylbenzene & 145 & $7.53 \div 0.09$ & 10.49 & 2.96 & $8.68 \div 0.14$ \\
\hline 1,2,3-Trimethylbenzene & & $8.54 \div 0.07$ & 11.40 & 2.86 & $9.40 \div 0.09$ \\
\hline 1.2.4-Trimethylbenzene & & $8.84 \pm 0.07$ & 11.63 & 2.79 & $9.67 \pm 0.07$ \\
\hline 1,3,5-Trimethylbenzene & 162.8 & $8.98 \pm 0.07$ & 11.85 & 2.87 & $9.74 \pm 0.09$ \\
\hline n-Propylbenzene & & $9.14 \pm 0.02$ & $\approx 11.92$ & $\approx 2.78$ & $10.20 \pm 0.03$ \\
\hline n-Butylbenzene & 182 & $10.52 \pm 0.02$ & 13.36 & 2.84 & $11.40 \pm 0.03$ \\
\hline Chlorobenzenes & ref. 18 & & ref. 18 & & \\
\hline Chlorobenzene & 127.1 & $6.44 \pm 0.05$ & 9.43 & 2.99 & $7.7 \div \pm 0.07$ \\
\hline$o$-Dichlorobenzene & 142.7 & $7.74 \pm 0.02$ & 11.40 & 3.66 & $8.94 \div 0.03$ \\
\hline m-Dichlorobenzene & 144.7 & $8.04 \pm 0.02$ & 11.12 & 3.08 & $9.05 \pm 0.03$ \\
\hline p-Dichlorobenzene & 144.7 & $7.90 \div 0.05$ & 11.40 & 3.50 & $8.98 \pm 0.07$ \\
\hline 1,2,3-Trichlorobenzene & 158.3 & $9.10 \pm 0.07$ & 12.02 & 2.92 & $9.97 \pm 0.09$ \\
\hline 1,2,4-Trichloroienzene & 160.2 & $9.3 \pm 0.2$ & 12.57 & 3.3 & $10.02 \div 0.25$ \\
\hline 1,3,5-Trichlorobenzene & 162.2 & $9.8 \pm 0.2$ & 13.38 & 3.6 & $10.24 \pm 0.28$ \\
\hline 1,2,3,4-Tetrachlorobenzene & 173.8 & 10.4 & 14.32 & 3.9 & 10.9 \\
\hline 1,2,3,5-Tetrachlorobenzene & 175.8 & 10.7 & 14.37 & 3.7 & 11.1 \\
\hline $1,2,4,5$-Tetrachlorobenzene & 175.8 & 10.7 & 14.21 & 3.5 & 11.1 \\
\hline Pentachlorobenzene & 189.4 & 12.1 & 15.66 & 3.6 & 12.1 \\
\hline Hexachlorobenzene & 203.0 & 13.6 & 17.20 & 3.6 & 13.1 \\
\hline Arenes & $\star$ & & refs. 39,40 & & \\
\hline Naphthalene & 153 & $8.01 \pm 0.08$ & 11.10 & 3.09 & $9.25 \div 0.12$ \\
\hline Biphenyl & 190 & $9.60 \pm 0.02$ & 12.98 & 3.38 & $10.78 \pm 0.03$ \\
\hline Fluorene & 181 & $9.8 \pm 0.2$ & 13.38 & 3.58 & $10.43 \pm 0.30$ \\
\hline Anthracene & 196 & $10.9 \pm 0.3$ & 14.66 & 3.76 & $11.40 \pm 0.39$ \\
\hline Phenanthrene & 196 & $10.5 \pm 0.3$ & 14.36 & 3.86 & $11.05 \pm 0.39$ \\
\hline Pyrene & 203 & $11.7 \div 0.3$ & 15.21 & 3.51 & $11.92 \pm 0.51$ \\
\hline
\end{tabular}

$\star$ Estimated values, using $A(=C-H)=18.25 A^{2}, A(\neq C-\text {, condensation })^{36}=3.49 A^{2}$ and $A(\equiv C$ alkyl) ${ }^{30}=4.98 \mathrm{~A}^{2}$

in contact with the adsorbent is denoted by $\psi=\bar{A}_{1} / A_{1}$. The obtained $\psi\left(\sigma_{23}^{0}-\sigma_{2 \cdot 3}^{0}\right)$ values for the three solute classes are $28.8 \pm 0.9$ (alkylbenzenes), $28.3 \pm 0.5$ (chlorobenzenes), $23.7 \pm 1.4$ (arenes) and $27.2 \pm 0.9 \mathrm{dyne} / \mathrm{cm}$ for the $-\mathrm{CH}_{2}-$ group. Thus. eqn. 11 offers a useful empirical description of the eluent effect on in $k$ values in the examined range [30-90\%(v/v) methanol] with plausible values of $\psi$. Within a group of related substances $\psi$ has a constant value, but slightly different values are obtained for different groups of substances. This result may mean that $\ln \bar{\gamma}_{1,2,3}^{\infty}-\ln \gamma_{1,2}^{\infty}$ is independent of the eluent composition in the examined range. However, it is unlikely 


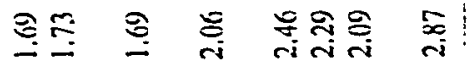

$\sum$

$\leqslant 0$

$: \leqslant s$,

ำ

$\sum 5$

은

$\equiv \mathrm{S}$

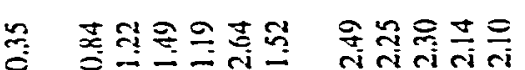

ชi

$*$

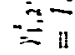

ฮิ

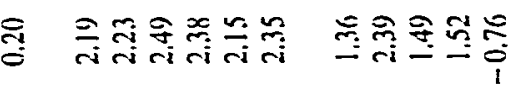

$\equiv s$

$\equiv \approx$

政

$=3$. $=1$

$=$

$\equiv 1$

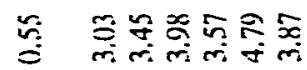

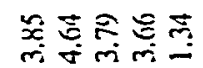

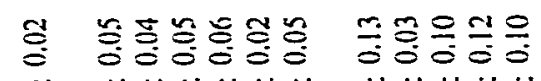

$\div \quad+1+1+H+1$

文 方

玄 方

$\div+H+H \div$

$气 \cong \approx \varpi \Xi$.

言竞

它 $\equiv$

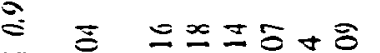

昰

$\sum^{2}$

항

$=0000$

$=\leq \quad \div \quad+4+H+\pi$

$\div \mathrm{VI}$

$\div=$

$\stackrel{\overbrace{}}{-}$

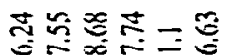

$+1+1+1+1 ;$

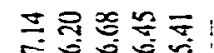

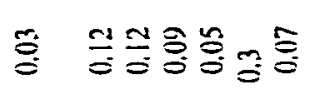

$\because=\quad+H+H+H+H$

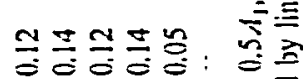

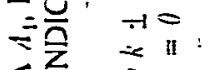

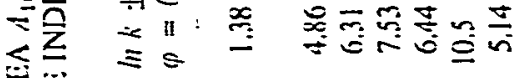

H $+\mathrm{H}+\mathrm{H}+\mathrm{H}$

11 总

$\simeq \equiv$

它

$\leqslant x: \leq$

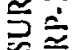

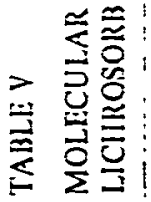

$\approx s$

웜요

으ㄴㅡㅡ

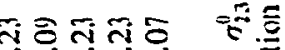

豆

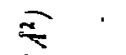

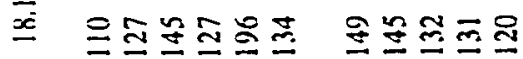

吾䓂

ーニニニミ

돈

$\bar{\Xi}$
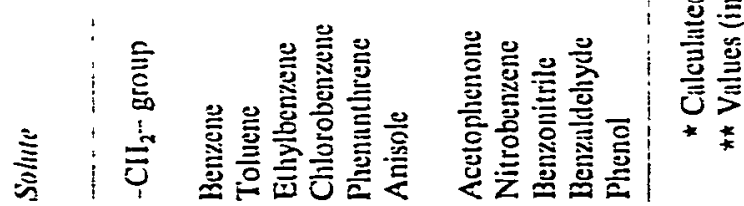
that the approximation $\ln \bar{\gamma}_{1.2 / 3}^{x}=\ln \gamma_{1.2}^{x}$, made in the derivation of eqn. 11 from eqn. 10 , is always true, as the surroundings of the solute in the bulk eluent and in the surface layer are rather different. It follows from the results of Möckel and Freyholdt ${ }^{23}$ that, for $n$-alkanes on Nucleosil C18 in $70 \%$ (v/v) methanol, $\ln \bar{\gamma}_{1,2 / 3}^{x}-\ln$ $\gamma_{1.2}^{\infty}$ increases linearly with the alkane chain length for the plausible value $\psi=0.5$. Therefore, Colin's model is not correct, although for a group of related solutes it may give a useful description of eluent effects.

Locke's model (eqns. 8 and 10). We consider first the (extrapolated) data on retention with water as the eluent. The data on $\ln \left(\mathrm{k} / \gamma_{1,2}^{x}\right)$ given in Table IV are, within a class of related solutes, independent of $A_{1}$. This result is difficult to reconcile with eqn. 8 , according to which $\ln \left(k / \gamma_{1,2}^{\infty}\right)$ is equal to $\ln \left(\bar{n}_{2} / n_{2}\right)-\ln \gamma_{1,2 / 3}^{x}$. It implies that the activity coefficient $\gamma_{1,2 / 3}^{\infty}$ is independent of $\bar{A}_{1}$. It will be difficult to develop a physical model that predicts this unexpected relationship -or rather, this absence of a relationship. This argument illustrates the superiority of eqn. 10 over eqn. 8. According to eqn. $10, \ln \left(k / \gamma_{1.2}^{\infty}\right)$ is equal to $\ln \left(\bar{n}_{2} / n_{2}\right)-\ln \bar{\gamma}_{1,2 / 3}^{x}+\bar{A}_{1} N\left(\sigma_{23}^{0}-\sigma_{13}^{0}\right) / R T$. It follows that the dependency of $\ln \bar{i}_{1,2 / 3}^{x}$ on $\bar{A}_{1}$ is compensated by that of the surface tension term.

Now we turn our attention to data in methanol-water mixtures. At $40-70 \%$ (v/v) methanol, Slaats $\% .45$ and Hennion et al. $^{46}$ obtained approximately constant $\ln$ $\left(k n_{2} / y_{1}^{x}\right)$ values for monosubstituted benzenes and phenanthrene, respectively, on home-made RP-18 phases. We have obtained the corresponding data on LiChrosorb RP-18. Our $\ln k$ values are presented in Table $V$ as extrapolated $\ln k$ values in water and $b$ values, together with mean $\ln y_{1,2 / 3}^{x}$ values obtained from eqn. 8 .

The latter data were calculated using $\ddot{\gamma}_{1.2}^{x}$ data given by Slaats ${ }^{44.45}$. Values for $n_{2}$ are based on $V_{\mathrm{m}}=$ $627 \mu \mathrm{l}$. Values for $\bar{n}_{2}$ are based on the weight of adsorbent in the column $(0.485 \mathrm{~g})$ and the amount of adsorbed eluent [at 50-90\% (v/v) methanol: $1.49 \mathrm{mmole}$ methanol and 0.22 mmole water per gram $\mathrm{Li}$ Chrosorb RP-18, according to Slaats ${ }^{19}$ ]. Activity coefficients of phenanthrene were obtained from molar solubility data $^{36}(S)$ using the equation

$$
\ln \left(y_{1,2}^{x} / y_{1, H_{2} \mathrm{O}}^{\mathrm{x}}\right)=\ln \left(S_{1, \mathrm{H}_{3} \mathrm{O}} v_{\mathrm{H}_{2} \mathrm{O}}^{\mathrm{O}} / S_{1,2} v_{2}^{0}\right)
$$

where $r^{\circ}$ is the molar volume, and in $i_{1 . H_{2} \mathrm{O}}^{x}$ is given in Table IV. The $\ln \left(7_{1.2}^{x}\right)_{\mathrm{CH}_{2}}$ data for a $-\mathrm{CH}_{2}-$ group are calculated from In $\left(r_{1.2}^{x} / k\right)_{\mathrm{CH}_{2}}$ values. $\operatorname{Ln}\left(i_{1.2}^{x}\right)_{\mathrm{CH}_{2}}$ is obtained from eqn. 19, using $A_{\mathrm{CH}_{2}}=$ $18.1 \AA^{2}$ and $C \sigma_{1,2}^{0}$ values given in Table II. The indicated uncertainty of the data in the fifth column of Table $\mathrm{V}$ corresponds with the (hardily significant) increase of $\ln 7_{1.2}^{x}$ with increasing methanol content.

The results in Table $\mathrm{V}$ give rise to the following comment. The $\ln \gamma_{1,2 / 3}^{x}$ values of the various apolar benzenes in 40-70\%(v/v) methanol are not correlated with $A_{1}$, just as is found in water as eluent. Obviously, also in methanol-water mixtures the dependency of $\ln \bar{\gamma}_{1,2 / 3}^{\infty}$ on $\bar{A}_{1}$ is roughly compensated by that of the surface tension term in eqn. 9. However, this compensation is not perfect for $n$-alkyl chains where In $\left(\gamma_{1,2 / 3}^{x}\right)_{\mathrm{CH}_{2}}=0.10$. This conclusion is confirmed by Möckel and Freyholdt's results ${ }^{43}$ obtained for a series of $n$-alkanes on Nucleosil $\mathrm{Cl} 8$ in $70 \%(\mathrm{v} / \mathrm{v})$ methanol. Hence, a description of $\ln k$ in terms of eqn. 10 is preferred. The differences in the values of $\ln$ $\gamma_{1,2 / 3}^{\infty}=\ln \bar{\gamma}_{1,2 / 3}^{\infty}-\bar{A}_{1} N\left(\sigma_{23}^{0}-\sigma_{13}^{0}\right) / R T$ are partly due to differences in $\ln \bar{\gamma}_{1,2 / 3}^{x}$ and partly due to different $\bar{A}_{1}$ and $\sigma_{13}^{0}$ values. For the investigated, relatively apolar solutes $\sigma_{13}^{0}$ is presumably very small. If we assume that $\bar{A}_{1}=0.5 A_{1}$ and that $\sigma_{23}^{0}=$ 
20 dyne/cm [i.e., equal to $\sigma_{23}^{0}$ for the tetradecane $/ 50 \%(v / v)$ methanol-water interface] and we neglect $\sigma_{13}^{0}, \ln F_{1,2 / 3}^{x}$ can be calculated at $50 \%(v / v)$ methanol. These data are given in the sixth column of Table $V$. They reflect the interactions of the solutes in the interfacial layer. As a monolayer of almost pure methanol is adsorbed to the RP18 surface layer, solute-methanol interactions reflected in the $\ln \gamma_{1,2}^{x}$ values holding in methanol (2') should also contribute to $\ln \bar{\gamma}_{1.2 / 3}^{x}$. Indeed, the range of $\ln \left(\vec{\gamma}_{1.2}^{x} / \gamma_{1.2}^{x}\right)$ values (eighth column of Table $V$ ) is much smaller than that of $\ln \overrightarrow{F i}_{1.273}(1.8 v s .3 .5$ ). Further, a comparison of the data for the polar benzenes in columns 6 and 8 clearly illustrates the importance of solute-methanol interactions in the interface. Solute adsorption to rcsidual silanol groups on LiChrosorb RP-18 is not apparent, because one regression holds for $\log k$ on $\log P_{\text {oct. }}$ values $\left(P_{\text {oct. }}\right.$ is the solute partition coefficient in the octanol-water system) for acidic chlorophenols, basic chloroanilines and apolar compounds ${ }^{47}$ (compare with results given in ref. 48 , where adsorption to silanol groups controls the retention).

The liquid-liquid partition model. In this model a linear In $k$ versus $\ln P$ plot with a slope close to 1 is expected (eqn. 17). Using $P_{\mathrm{Cl}_{16}}$ data in the system $n$ hexadecane $150 \%(\mathrm{v} / \mathrm{v})$ methanol-water ${ }^{-9}$ at $25^{\circ} \mathrm{C}$, such a plot is found for the apolar solutes benzene, toluene and chlorobenzene:

$$
\ln k=1.70+\ln P_{\mathrm{C} 16}
$$

A similar correlation is obtained for apolar solutes between $\ln k$ values in water and $\ln$ $P$ values in a water $/ n$-heptane system ${ }^{* 8}$, where $\ln k=\ln P_{\mathrm{C} 7}$. Both intercepts are mach larger than expected from the phase ratio term in eqn. 17. Hence. solute partition (with the assumption $7_{1.3}^{x}=\%_{1.3}^{x}$ ) is inadequate to predict in $k$ values of apolar solutes on LiChrosorb RP-18 (eqn. 18).

The $\ln k$ values of the polar benzenes are larger than expected from eqn. 23 (see last column of Table $\mathrm{V}$ ). This points to a particularly favourable sorption mode for these molecules. presumabiy one in which the polar part interacts with the adsorbed methanol layer. This is most clear for phenol. both from $\ln \left(k / P_{\mathrm{c}_{16}}\right)$ and from a comparison of $\ln \boldsymbol{F}_{1.2}$ and $\ln \left(\bar{\gamma}_{1.2} / \gamma_{1.2}\right)$ data. In this connection it is worth noting that addition of only $2 \%$ chloroform to the eluent methanol-water $(1: 1)$ causes a relatively large reduction of in $k$ values of phenols on ODS-silica ${ }^{50}$. This result can be attributed to competitive Lewis base-Lewis acid interaction in the interfacial methanol layer.

Horvátlis model. This interesting model will be examined by means of $\ln (\mathrm{k})_{\mathrm{CH}_{2}}$ values. Because of the large number of unknown model parameters only approximate equations have been examined up till now. Horváth et al. ${ }^{25}$ showed that $\ln k$ values of solutes increase with their hydrocarbonaceous surface area (when polar interactions are similar). This result is in accord with eqn. 57 of ref. 25

$$
\ln k \approx \text { constant }+\sigma_{2}^{0}\left(A_{1}+A_{3}-A_{13}\right) N / R T
$$

where $A_{1}+A_{3}-A_{13} \equiv A A$ is the total surface area of the solute molecule (1) and the adsorbent (3) that loses contact with the eluent (2) on adsorption. But as $\Delta A$ is proportional to $A_{1}$, the same result is expected for solute partition (combine eqns. I5 and 7). A more severe test should involve the term $\sigma_{2}^{0} \Delta A$. Therefore. we consider the 
equation:

$$
\ln (k)_{\mathrm{CH}_{2}} \approx \sigma_{2}^{\circ} \Delta A_{\mathrm{CH}_{2}} N / R T
$$

Using literature data for $\sigma_{2}^{0}$ and $A_{\mathrm{CH}_{2}}=18.1 \AA^{2}$, the following $\left.\Delta A_{\mathrm{CH}_{2}}\right\rfloor A_{\mathrm{CH}_{2}}$ values are obtained: 0.43 in water, 0.42 in $70 \%(\mathrm{v} / \mathrm{v})$ methanol and 0.18 in methanol as eluent. Obviously, eqn. 25 fails correctly to predict the eluent effect on in $k$. This may be due to unallowed approximations.

This problem can be overcome by using eqn. 14 and $\ln (k)_{\mathrm{CH}_{3}}$ data in water (2) and methanol $\left(2^{\prime}\right)$. Neat solvents are chosen for reasons given in the theoretical section. $\mathrm{Ln}\left(\gamma^{\infty}\right) \mathrm{CH}_{2}$ values can be estimated from eqn. $7(C=0.619$ in water and 1.02 in methanol). Substitution of these data reveals that the last term of the right-hand side of eqn. 14 is zero. As $\kappa_{2}^{\mathrm{c}}(3) \sigma_{2}^{0}-\kappa_{2}^{\mathrm{c}}$ (3) $\sigma_{2}^{0}$. is positive for $\kappa^{\mathrm{c}}$ and $\sigma^{0}$ values given by Halicioglu and Sinanoğlu ${ }^{51}, A_{13}-A_{3}$ is zero. This result suggests that the alkyl chains are immersed in the RP-18 layer. However, in that case it is hard to explain that $\ln \left(\gamma_{1,2 / 3}^{\infty}\right)_{\mathrm{CH}_{2}}$ is different from zero at $40-70 \%$ methanol (Table V). It is noted that when Sinanoğlu's solvophobic interaction theory is applied to solute adsorption in RP-18 columns, the magnitude of the parameters $\kappa^{-t}$ and $A_{13}-A_{3}$ in eqn. 24 should be known precisely. This is only the case when we are dealing with an impenetrable and regularly associated RP-18 layer that is smooth on a molecular scale. The occurrence of such ideal bonded phase surface layers is questionable.

Apart from the problems mentioned above. Horvatth's model has a fundamental shortcoming because it fails to account for contributions of solute-methanol interactions in the interfacial layer. This is due to the assumption $\Delta F_{13, j}^{\text {int }}=\Delta F_{3, j}^{\text {int. }}$ and the subsequent substitution of $\chi_{i, j}=-\Delta F_{i, j}^{\mathrm{eav}}$ underlying eqn. $A 7$ in the Appendix. This problem is hard to solve at an acceptable level of sophistication, because the interfacial methanol concentration changes outside the linear range of the excess isotherm ${ }^{19}$.

We conclude this section by stating that neither the adsorption models proposed by Colin and by Horvath nor a partition model can satisfactorily describe solute retention in RP-18/methanol-water systems. The $\ln (k / P)$ and the $\ln \left(\bar{\gamma}_{1.2 / 3}^{x} / s_{1.2}^{x}\right)$ data indicate that solute adsorption is of prime importance. Presumably, the adsorptive properties of RP-18 deviate from those of solid adsorbents due to solute sorption into the alkyl layer, the extent of which may depend on the polarity (interaction with adsorbed methanol) of the solute. More experimental data are necessary in order to improve on this rough picture. Finally, it is emphasized that these tentative conclusions should not be generalized to other reversed-phase systems. The present approach may prove useful to characterize their (ad)sorptive properties.

\section{CONCLUSIONS}

Values of $\ln \gamma_{1,2}^{\infty}$ at infinite dilution in water for solutes of different sizes, shapes and polarities are linearly related to the product of the interfaciai tension, $\sigma_{12}^{0}$, and the molecular surface area of the solute $A_{1}$, if $\sigma_{12}^{0} \geq 10$ dyne $/ \mathrm{cm}$. Similar plots of $\ln \gamma_{1.2}^{\alpha}$ vs. $A_{1} \sigma_{12}^{0}$ have been obtained for tetraalkyl compounds in methanol-water mixtures and for water in some organic solvents. All these plots have a common intercept but their slopes are different. The standard deviations around the regression lines are 
about 0.2 . This corresponds with an accuracy of $20 \%$, i.e., roughly four times the precision of the experimental $\eta^{\infty}$ data.

Solute retention on LiChrosorb RP-18 with methanol-water mixtures and water as eluents is mainly controlled by the solute activity coefficiert in the mobile phase. The adsorbent affinity towards solutes is approximately constant in the examined range of $40-70 \%(\mathrm{v} / \mathrm{v})$ methanol. This is due to a constant amount of adsorbed methanol in this range. In water and in methanol-water mixtures, $\ln \gamma_{1,2 / 3}^{x}$ is not related to the molecular surface area of the solute (alkyl chains are exceptions). Interactions between polar benzenes and methanol play an analogous rôle in the interfacial layer. This is most cleariy illustrated for phenol. It cannot be ruled out that the phenyl group of these solutes is partly surrounded by RP-18 chains, as seems to be the case for the apolar benzenes. But even for apolar solutes interfacial adsorption prevails.

The model proposed by Colin fails accurately to predict the eluent effects on solute retention and may give rise to misinterpretations. The solvophobic interaction model proposed by Horváth ignores solute interactions with adsorbed methanol and fails to describe the effects of neat eluent on $\ln k$ values of $n$-alkanes (or alkyl chains) in a plausible manner.

A better characterization of the surface structure of the RP-18 layer is desirable in order to improve the interpretation of retention data on more or less diffuse apolar bonded phase adsorbents. A presentation of the results in this work in terms of Locke's model (eqn. 10) is preferred.

APPENDIX

Derivation of eqns. 13 and 14

The standard partial molar free energy of solution of a solute $i$ in a solvent $j$ from the vapour state is given by:

$$
\mathcal{A} \mu_{i, \mathrm{j}}^{0}(\mathrm{v} \rightarrow \mathrm{s})=R T \ln \left(\overline{f_{i}} / x_{\mathrm{i}, \mathrm{j}}\right)=R T \ln \gamma_{i, \mathrm{j}}^{x} f_{\mathrm{i}}^{0}
$$

Therein $\vec{f}_{i}$ is the (partial) fugacity of $i$ that is in equilibrium with the solution of $i$ in $j$ at temperature $T$. The activity coefficient $\gamma_{i, j}^{x}$ is related to the pure solute $\left(\gamma_{i, j}^{x}=1\right.$, when $x_{i, j}=1$ ). and $f_{i}^{0}$ is the fugacity of the pure vapour of $i$ at temperature $T$. From the solubility theory of Pierotti ${ }^{52}$ it follows that at atmospheric pressure and at $x_{i-i} \approx 0$ :

$$
\Delta \mu_{i, j}^{\mathrm{o}}(\mathrm{v} \rightarrow \mathrm{s})=-\chi_{i, j}+R T \ln \left(R T / v_{j}^{\circ}\right)
$$

The second term of the right-hand side of this equation accounts for the change of the translational free energy of the solute molecules upon transfer from the perfect vapour state to the dissolved state. $v_{j}^{\circ}$ is the molar volume of the solvent. The term $-\chi_{i, j}$ represents the potential free energy of the solute molecules in solution (relative to that in the perfect vapour). It is the sum of the free energies of cavity formation, $\Delta F_{i, j}^{\mathrm{cas}}$, and of solute-solvent interactions, $\Delta F_{\mathrm{i}, \mathrm{j}}^{\mathrm{int}}$. According to Sinanoglu ${ }^{26}$ the former is given by*

$$
\Delta F_{i, j}^{\mathrm{eav}}=\kappa_{\mathrm{j}}^{\mathrm{e}}(\mathrm{i}) \sigma_{\mathrm{j}}^{0} A_{\mathrm{i}} N
$$

* The parameter $W_{\text {ij }}$ (see eqn. 20 of ref. 26 ) is omitred because it will enlarge $k^{-\varepsilon}$ only slightly ( $5 \%$ or less). 
where $\kappa_{j}^{e}(\mathbf{i}) \sigma_{j}^{0}$ is the "microscopic" surface tension of the curved cavity in $j$ accommodating the solute molecule $\mathrm{i}$, and $A_{\mathrm{i}} N$ is the molecular surface area per mole of solute. Combination of eqns. A1-A3 gives:

$$
\ln \gamma_{i, j}^{x}=\Delta F_{i, j}^{i n t} / R T+\kappa_{j}^{c}(i) \sigma_{j}^{o} A_{i} N / R T-\ln v_{j}^{o}+\ln \left(R T / f_{i}^{0}\right)
$$

Combination of analogous expressions for $\ln \gamma_{i, j}^{x}$ in the solvents $j=2$ and $j=2^{\prime}$ gives eqn. 13.

The interaction between the molecular species 1 and 3 can be characterized by the association constants $K_{13 . j}$ (in solvent $\mathrm{j}$ ) and $K_{13, \mathrm{v}}$ (in the vapour phase):

$$
K_{13, \mathrm{j}}=x_{13, \mathrm{j}} / x_{1, \mathrm{j}} x_{3, \mathrm{j}} \text { and } K_{13, \mathrm{v}}=\bar{f}_{13} / \bar{f}_{1} \overline{f_{3}}
$$

Combination of eqns. A5, A1 and A2 gives:

$$
\ln K_{13, j}=\ln K_{13, v}+\left(\chi_{13, j}-\chi_{3, j}\right) / R T+\ln \left(\gamma_{1, j}^{\infty} f_{1}^{0}\right)
$$

If it is assumed ${ }^{25}$ that $\Delta F_{13, j}^{\text {int. }}=\Delta F_{3, j}^{\text {int. }}$, implying that reduction terms ${ }^{26}$ can be omitted, and that $\kappa_{j}^{\mathrm{e}}(13)=\kappa_{j}^{\mathrm{c}}(3)$, substitution of $\chi_{i, j}=-\Delta F_{i, j}^{\mathrm{css}}$ according to eqn. A3 in eqn. A6 yields:

$$
\ln K_{13, j}=\ln K_{13, v}-\kappa_{j}^{e}(3) \sigma_{j}^{0}\left(A_{13}-A_{3}\right) N / R T+\ln \left(\gamma_{1, j}^{x} f_{1}^{0}\right)
$$

When the ligand 3 is chemically bound to a silica surface, the magnitude of $\bar{K}_{13 . j}=$ $\bar{x}_{13, j} / x_{1, j} \bar{x}_{3, j}$ may deviate from $K_{13, j}$ given by eqn. A5. In that case the chromatographic capacity ratio, $k_{1, j}, 3$, is given by:

$$
\ln k_{1, j / 3} \equiv \ln \left(n_{13, j} / n_{1, j}\right)=\ln \left(\bar{n}_{\mathrm{j}} / n_{\mathrm{j}}\right)+\ln \left(\bar{K}_{13, \mathrm{j}} \bar{x}_{3, \mathrm{j}}\right)
$$

\begin{tabular}{|c|c|}
\hline$\ddot{r}$ & - activity coefficient (standard state: pure liquid solute) \\
\hline$y^{\infty}$ & - activity coefficient at infinite dilution \\
\hline$\gamma^{x}$ & $\begin{array}{l}\text { - activity coefficient at standard state of monolayer of adsorbed } \\
\text { pure liquid solute }\end{array}$ \\
\hline$\delta$ & - empirical parameter \\
\hline$\kappa_{\mathbf{j}}^{\mathrm{e}}(\mathbf{i})$ & $\begin{array}{l}\text { - parameter that corrects } \sigma_{j}^{0} \text { for the effect of the curvature of the } \\
\text { cavity accommodating solute i in solvent } j \text { (eqn. A3) }\end{array}$ \\
\hline$\Delta \mu^{E}$ & - excess chemical potential \\
\hline$\Delta \mu^{\text {sth. }}$ & - athermal contribution to $\Delta \mu^{\mathrm{E}}$ \\
\hline$\Delta \mu^{\text {th }}$. & - thermal contribution to $\Delta \mu^{\mathrm{E}}$ \\
\hline$\Delta \mu^{\circ}($ & $\begin{array}{l}\text { - standard partial molar free energy of solution from the perfect } \\
\text { vapour }\end{array}$ \\
\hline $\mathbf{0}$ & - surface tension \\
\hline
\end{tabular}

If one can assume that the ratio $\bar{K}_{13, j} / K_{13 . j}$ (and the accessibility of the bound ligands for solute molecules) is similar in various solvents, substitution of eqn. A7 in A8 yields expressions for $\ln k_{1, j^{\prime} 3}$ in the solvents 2 and $2^{\prime}$. Combination gives eqn. 14.

\section{SYMBOLS}


$\sigma^{\mathbf{d}}$

$\sigma_{i j}^{0}$

$\Phi$

$\varphi$

$-\%$

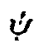

$\frac{A}{A}$

$A A$

$B$

C

$F^{c}$

$-F^{2}$

$\Delta F^{\text {sas }}$

$\Delta F^{\text {int. }}$

$K$

$\bar{K}$

$N$

$P$

$R$

$S$

$T$

$V_{\text {m }}$

$V_{\mathrm{r}}$

$V_{\mathrm{s}}$

$V_{0}$

$c$

$\bar{f}$

$f^{\circ}$

k

$n$

$\bar{n}$

$r$

$r^{0}$

$x$
- dispersive part of surface tension (eqn. 12)

- interfacial tension between the phases $i$ and $j$

- measure for the deviation from the geometric mean rule

- volume fraction of methanol in the eluent

- potential free interaction energy relative to that in perfect vapour (eqn. A2)

- fraction of the molecular surface area in contact with the adsorbent phase

- molecular surface area

- area occupied by a solute molecule on the adsorbent

- surface area of adsorbate molecule and adsorbent that loses contast with the eluent on solute adsorption

- empirical parameter (eqn. 7)

- empirical parameter (eqn. 7)

- free energy of cohesion per $\mathrm{cm}^{2}$

- free energy of adhesion per $\mathrm{cm}^{2}$

- free energy of cavity formation (eqn. A3)

- free energy of interaction

- association constant (free ligand. eqn. A5)

- association constant (bonded phase ligand)

- Avogadro's constant

- solute partition coefficient

- gas constant

- molar solubility

- absolute temperature

- volume of the mobile eluent in the column

- retention volume corrected for hold-up outside the column

- volume of adsorbed eluent in the column

- volume of the empty column minus the volume of the packing material

- concentration (mole/1)

- partial fugacity

- fugacity

- chromatographic capacity ratio

- number of moles (dissolved in mobile phase)

- number of moles (adsorbed or sorbed)

- mean molecular radius

- molar volume

- mole fraction

\section{REFERENCES}

1 G. J. Pierotti, C. H. Deal and E. L. Derr, Ind. Eng. Chem., 51 (1959) 95.

2 A. J. Ashworth and D. H. Everett. Trans. Faraday. Soc., 56 (1960) 1609.

3 M. L. Huggins. J. Chem. Phys., 9 (1941) 410.

4 P. J. Flory, J. Chem. Phys., 9 (1941) 660.

5 J.H. Hildebrand and R. L. Scott, Regular Solutions, Prentice-Hall, Englewood Clifis, New York, 1962, Ch. 3. 
6 M. Vitoria and J. Walkley, Trans. Faraday Soc., 65 (1962) 57.

7 P. J. Fory, Disc. Faraday Soc., 49 (1970) 7.

8 L. A. Girifalco and R. J. Good, J. Phys. Chem., 61 (1957) 904.

9 H. H. Uhlig, J. Phys. Chem., 41 (1937) 1215.

10 D. S. Choi, M. S. Jhon and H. Eyring, J. Chem. Phy:s., 53 (1970) 2608.

11 A. Ben-Naim, Hydrophobic Interactions, Plenum, New York, 1980, p. 40.

12 F. M. Fowkes, J. Phys. Chem., 66 (1962) 1863.

13 K. Hallenga, J. R. Grigera and H. J. C. Berendsen, J. Phys. Chem., 84 (1980) 2381.

14 D. Patterson and M. Barbe, J. Phys. Chem., 80 (1976) 2435.

15 K. Shinoda, J. Phys. Chem., 81 (1977) 1300.

16 R. B. Hermann, J. Phis. Chem., 76 (1972) 2754.

17 G. L. Amidon, S. H. Yalkowsky and S. Leung, J. Pharm. Sci., 63 (1974) 1858.

18 S. H. Yalkowsky. R. J. Orr and S. C. Valvani, Ind. Eng. Chem., Fundam., 18 (1979) 351.

19 E. H. Slazts, W. Markovski. J. Fekete and H. Poppe, J. Chromatogr., 207 (1981) 299.

20 D. H. Everett, Trans. Faraday Soc., 61 (1965) 2478.

21 D. C. Locke, J. Chromatogr. Sci., 12 (1974) 433.

22 H. Colin and G. Guiochon. J. Chromatogr.. 158 (1978) 183.

23 C. H. Eon, Anal. Chem., 47 (1975) 1871 .

24 F. M. Fowkes, J. Phys. Chem., 67 (1963) 2538.

25 Cs. Horváth, W. Melander and I. Molnár, J. Chromatogr., 125 (1976) 129.

26 O. Sinanoglu, in B. Pullman (Editor), Proc. Internat. Conf. Molec. Assoc. Biol.. Academic Press, New York, 1968, p. 427.

27 H. Hemetsberger, W. Maasfeld and H. Ricken. Chromutographia, 9 (1976) 303.

28 W. D. Harkins and A. E. Alexander, in A. Weissberger (Editor), Technique of Organic Chemistry I(1), Interscience, New York, 1959. Ch. XIV.

29 S. C. Valvani, S. H. Yalkowsky and G. L. Amidon. J. Phys. Chem., 80 (1976) 829.

30 P. Pomerantz, W. C. Clinton and W. A. Zisman, J. Colloid Interface Sci., 24 (1976) 16.

31 C. McAuliffe, J. Phys. Chem., 70 (1966) 1267.

32 C. Sutton and J. A. Calder, J. Chem. Eng. Data, 20 (1975) 320.

33 D. J. Donahue and F. E. Bartell, J. Phys. Chem., 56 (1952) 480.

34 A. Seidell, Solubilities of Organic Compounds, Van Nostrand, New York. 1941.

35 G. H. Bell, Chem. Phys. Lipids. 10 (1973) 1.

36 A. Bondi, J. Phys. Chem., 68 (196-1) 441.

37 C. L. de Ligny and N. G. van der Veen, Rec. Tras. Chim. Pays-Bas, 99 (1971) 984.

38 K. O. Hiller, B. Masloch and H. J. Möckel. Z. Anal. Chem., 283 (1977) 109.

39 D. Mackay and W. Y. Shiu, J. Chem. Eng. Data, 22 (1977) 399.

40 W. E. May, S. P. Wasik and D. H. Freeman, Anal. Chem., 50 (1978) 997.

41 R. M. McCormick and B. L. Karger, Anal. Chem., 52 (1980) 2249.

42 B. L. Karger, J. R. Grant, A. Hartkopf and P. H. Weiner, J. Chromatogr., 128 (1976) 65.

43 H. J. Möckel and T. Freyholdt, Z. Anal. Chem., 368 (1981) 401.

44 E. H. Slaats, Thesis, University of Amsterdam, Amsterdam, 1980.

45 E. H. Slaats, S. Heemstra and H. Poppe, J. Chromatogr., in preparation.

46 M. C. Hennion, C. Picard, C. Combelias, M. Caude and R. Rosset, J. Chromatogr., 210 (1981) 211.

47 W. E. Hammers, G. J. Meurs and C. L. de Ligny, J. Chromatogr., 247 (1982) 1.

48 W. E. Hammers, R. H. A. M. Janssen, A. G. Baars and C. L. de Ligny, J. Chromatogr., 167 (1978) 273.

49 M. C. Spanjer and C. L. de Ligny, J. Chromatogr., submitted for publication.

50 R. M. McCormick and B. L. Karger, J. Chromatogr., 199 (1980) 259.

51 T. Halicioğlu and O. Sinanoğlu, Ann. N.Y. Acad. Sci., 158 (1969) 308.

52 R. A. Pierotti, J. Phys. Chem., 67 (1963) 1840. 